\title{
Identificação de constituintes opticamente ativos na água do Lago Guaíba a partir de dados de sensores orbitais e espectrorradiometria de campo
}

\author{
Gustavo Rodrigues TONIOLO ${ }^{1}$, Laurindo Antonio GUASSELLI ${ }^{1,2}$, Diniz Carvalho de ARRUDA ${ }^{1}$ \& \\ Waterloo PEREIRA FILHO ${ }^{3}$
}

Programa de Pós-Graduação em Sensoriamento Remoto, Universidade Federal do Rio Grande do Sul. Av. Bento Gonçalves, 9500, CEP 91501-970, Porto Alegre, RS, Brasil (gustavotoniolo1@gmail.com, dinizcarvalho88@gmail.com).

Programa de Pós-Graduação em Geografia, Universidade Federal do Rio Grande do Sul. Av. Bento Gonçalves, 9.500, CEP 91540 -000, Porto Alegre, RS, Brasil (laurindo.guasselli@ufrgs.br).

3 Programa de Pós-Graduação em Geografia, Universidade Federal de Santa Maria. Av. Roraima, 1000. CEP 97105-900, Santa Maria, RS, Brasil (waterloopf@gmail.com).

Toniolo, G.R., Guasseli L.A., Arruda, D.C de \& Pereira Filho, W. 2018. Identificação de constituintes opticamente ativos na água do Lago Guaíba a partir de dados de sensores orbitais e espectrorradiometria de campo. Pesquisas em Geociências, 45: e0635.

DOI: https://doi.org/10.22456/1807-9806.88645

Resumo. 0 Lago Guaíba é a principal fonte de abastecimento de água para a região metropolitana de Porto Alegre. Os sensores remotos são cada vez mais utilizados na discriminação de diferentes elementos presentes na água. 0 objetivo deste trabalho é identificar os constituintes opticamente ativos da água do Lago Guaíba, quanto às suas propriedades ópticas, a partir da integração de dados de sensoriamento remoto orbital e de espectrorradiometria de campo. Para tanto foram coletadas e relacionadas variáveis limnológicas e espectrais. Técnicas de derivada foram utilizadas, buscando identificar os constituintes opticamente ativos que determinam as características da água. Uma imagem do sensor LISS-III/ResourceSat-2 foi usada para estimativa empírica dos parâmetros limnológicos. Os resultados mostram que regressões empíricas explicam que $23 \%$ da reflectância em 708 nm é devida a presença de sólidos na água, e a concentração de Chl- $a$ não apresentou correlações significativas $(\alpha=0,05)$ com a reflectância. A partir da análise dos dados espectrais pela Técnica de derivada, observa-se o aumento das correlações após a derivação evidenciando que esta técnica aumenta o contraste espectral e assim a precisão das estimativas. A primeira derivada em $772 \mathrm{~nm}$ explicou 44\% da variação devido aos totais de sólidos suspensos. Já em $690 \mathrm{~nm}$, a primeira derivada explicou $32 \%$ da variação na concentração de clorofila-a. Os melhores resultados foram observados nas variáveis turbidez e transparência da água. As imagens LISS-III mostraram-se potenciais para mapear a composição da água do Lago Guaíba, por meio de regressões lineares.

Palavras-chave. Sensoriamento remoto da água, Limnologia, Regressão empírica, LISS-III, Primeira derivada, Espectro de reflectância.

\begin{abstract}
IDENTIFICATION OF OPTICALLY ACTIVE CONSTITUENTS IN WATER FROM THE GUAÍBA LAKE FROM ORBITAL SENSORS DATA AND FIELD SPECTRORADIOMETRY. The Guaíba Lake is the main source of water supply to Porto Alegre metropolitan region. Remote sensing is increasingly used for the discrimination of the different elements presented in water. This work aims to identify the active optically constituents of the water of Guaíba Lake, as regards their optical properties, from integration of data orbital remote sensing and spectroradiometry in field. To achieve this, limnologic and spectral variables were collected and related. Derivation techniques were applied in order to identify the optically active constituents, which determine the characteristics of the water. An image of the sensor LISS-III/ResourceSat- 2 was used for the empirical estimation of the limnologic parameters. The results showed that empirical regressions explained that $23 \%$ of the reflectance in $708 \mathrm{~nm}$ is due to the presence of solids in the water, and the concentration of Chl- $a$ did not present significant correlations $(\alpha=0,05)$ with the reflectance. From the analysis of the spectral data by the Derivative technique, was observed the increase of correlations after the derivation, highlighting the fact that this technique increases the spectral contrast and so the estimation accuracy. The first derivation in $772 \mathrm{~nm}$ explained $44 \%$ of the variation due to total suspended solids. Already in $690 \mathrm{~nm}$, the first derivation explained $32 \%$ of the variation in the concentration of chlorophyll-a. The best results were observed in the turbidity and water transparency variables. The images LISS-III showed themselves to be potentials to map Guaíba Lake composition, by means of linear regressions.
\end{abstract}

Keywords. remote sensing of water, limnology, empirical regression, LISS-III, first derivative, reflectance spectrum. 


\section{Introdução}

O Lago Guaíba é um importante corpo d'água, localizado na porção leste do estado do Rio Grande do Sul, em que deságuam oito sub-bacias que se estendem pelo centro e nordeste do estado, formando a Região Hidrográfica do Guaíba. 0 Lago Guaíba é formado a partir do deságue dos rios Gravataí, Sinos, Caí e Jacuí e banha o principal polo econômico e político do estado, o município de Porto Alegre (FEPAM, 2015). Além de possuir localização privilegiada, exerce ainda funções sociais primordiais a estes municípios adjacentes, como de estocar água para usos futuros, abastecimento urbano, agrícola e industrial. A região metropolitana de Porto Alegre (RMPA) é a mais densamente habitada do Estado, com mais de 4 milhões de habitantes, que responde por quase $70 \%$ do PIB do Estado (IBGE, 2010).

Nas últimas décadas o lançamento de esgotos domésticos da RMPA e de resíduos industriais nos rios Gravataí e Sinos, na região metropolitana, foram responsáveis por degradar a qualidade das águas do Guaíba (Bendati \& Kirchheim, 1998; Jobim, 2012). Desta maneira, a poluição vem comprometendo não somente a qualidade da água utilizada para abastecer a população, mas também de forma permanente o ecossistema aquático como um todo.

A heterogeneidade dos ecossistemas aquáticos expressas pelos constituintes opticamente ativos (COAs) vêm sendo monitorados por meio de dados de sensoriamento remoto, tanto em nível orbital, quanto em campo. A aplicabilidade destas técnicas e ferramentas é bastante contextualizada na literatura (Rudorff et al., 2007; Jensen, 2011; Londe et al., 2011). A utilização de dados adquiridos tanto em nível orbital quanto de campo, para o monitoramento dos componentes ópticos da água, tem como base o fato de que estes são determinados pela concentração de sedimentos em suspensão, fitoplâncton e matéria orgânica dissolvida, chamados de constituintes opticamente ativos (COAs), pois alteram as propriedades espectrais da água pura (Dekker, 1993; Felix, 1993; Rudorff et al., 2007).

Ao se conduzir uma pesquisa de sensoriamento remoto da água é importante ter o entendi- mento de que a resposta espectral da água (Jensen, 2011; Lissner \& Guasselli., 2013) se restringe a uma faixa relativamente estreita de comprimento de onda. Isto é causado pela baixa irradiância solar de comprimentos de onda mais curtos que aproximadamente $400 \mathrm{~nm}$, e por uma combinação de baixa energia solar e o nítido aumento da absorção da luz pela água acima de aproximadamente 850 nm. Desta maneira, o intervalo de 400 a $850 \mathrm{~nm}$ é o mais recomendado para o sensoriamento remoto da água (Dekker, 1993; Jensen, 2011).

Com o avanço dos sensores hiperespectrais portáteis, um dos enfoques para se reduzir o efeito dos componentes aditivos na água, que não contém a informação de interesse, é a análise derivativa. Rudorff et al. (2007) utilizaram análise derivativa hiperespectral para mapear a composição das águas utilizando conjunto de dados Hyperion. Goodin et al. (1993) demonstram que a primeira derivada permite remover o sinal de reflectância da água, facilitando a detecção de sedimentos em suspensão, e que a segunda derivada remove o efeito espectral das partículas inorgânicas em suspensão, mantendo nos dados apenas a informação associada à presença da clorofila.

As imagens de satélite são produtos importantes nos estudos ambientais. Os dados da série Landsat, atualmente com o sensor OLI (Operational Land Imager) do satélite Landsat-8, e do sensor LISS-3 (Linear Imaging Self-Scanning Sensor-3), a bordo do satélite ResourceSat-2, são gratuitas e possuem uma ampla cobertura temporal. Mas a utilização das imagens dessas sensores para avaliação das condições de ecossistemas aquáticos ainda é bastante restrita (Brochado \& Macarringue, 2014), havendo necessidade de mais estudos.

0 objetivo deste trabalho é identificar os constituintes opticamente ativos da água do Lago Guaíba, quanto às suas propriedades ópticas, a partir da integração de dados de sensoriamento remoto orbital e de espectrorradiometria de campo.

\section{2 Área, materiais e métodos}

\subsection{Localização da área}

O Lago Guaíba localiza-se no estado do Rio 
Grande do Sul, entre as coordenadas $29^{\circ} 55^{\prime}$ e $30^{\circ} 24^{\prime}$ de latitude Sul e entre $51^{\circ} 01^{\prime}$ e $51^{\circ} 20^{\prime}$ de longitude Oeste (Figura 1). A Região Hidrográfica do Guaíba compreende nove bacias e apresenta uma área de aproximadamente $85 \mathrm{mil} / \mathrm{km}^{2}$.

0 Lago Guaíba é formado principalmente pela contribuição dos rios Jacuí, dos Sinos, Caí e gravataí. $\mathrm{O}$ curso inferior dos canais destes rios converge para o delta do Jacuí e daí seguem pelo leito do Lago Guaíba até a ponta do Itapuã (Bendati \& Kirchheim, 1998). Ao Sul este canal desaparece no leito da Lagoa dos Patos por soterramento e suas águas seguem na sequência para o Oceano Atlântico (Toldo Jr. \& Almeida, 2009; Andrade Neto et al., 2012).

0 tipo de clima na região do Lago Guaíba, segundo a classificação de Rossato (2011) é Subtropical II e III, de úmido para medianamente úmido com variações longitudinais das temperaturas mé- dias. Apresenta maior influência dos sistemas polares e tropicais continentais, porém com interferência crescente dos sistemas tropicais marítimos. Influenciam também o relevo (Depressão Central), a continentalidade e a maritimidade, além das áreas urbanizadas. Os sistemas frontais são responsáveis pela maior parte das precipitações. As chuvas podem oscilar entre 1500 a $1800 \mathrm{~mm}$ anuais e a temperatura média anual varia entre 17 a $20^{\circ} \mathrm{C}$.

Estendendo-se desde o delta do Jacuí até a ponta de Itapuã do Sul (direção N-S), o Guaíba tem aproximadamente $50 \mathrm{~km}$ de comprimento, 470 $\mathrm{km}^{2}$ de superfície e profundidade média de $2 \mathrm{~m}$. Sua largura é variável, sendo a mínima de $900 \mathrm{~m}$ e máxima de $19 \mathrm{~km}$, com formações graníticas na parte leste e pontas arenosas na margem oeste. 0 regime de escoamento das águas do Guaíba é bidimensional, podendo ser longitudinais e transversais ao seu canal (Livi, 1998; Nicolodi et al., 2010).

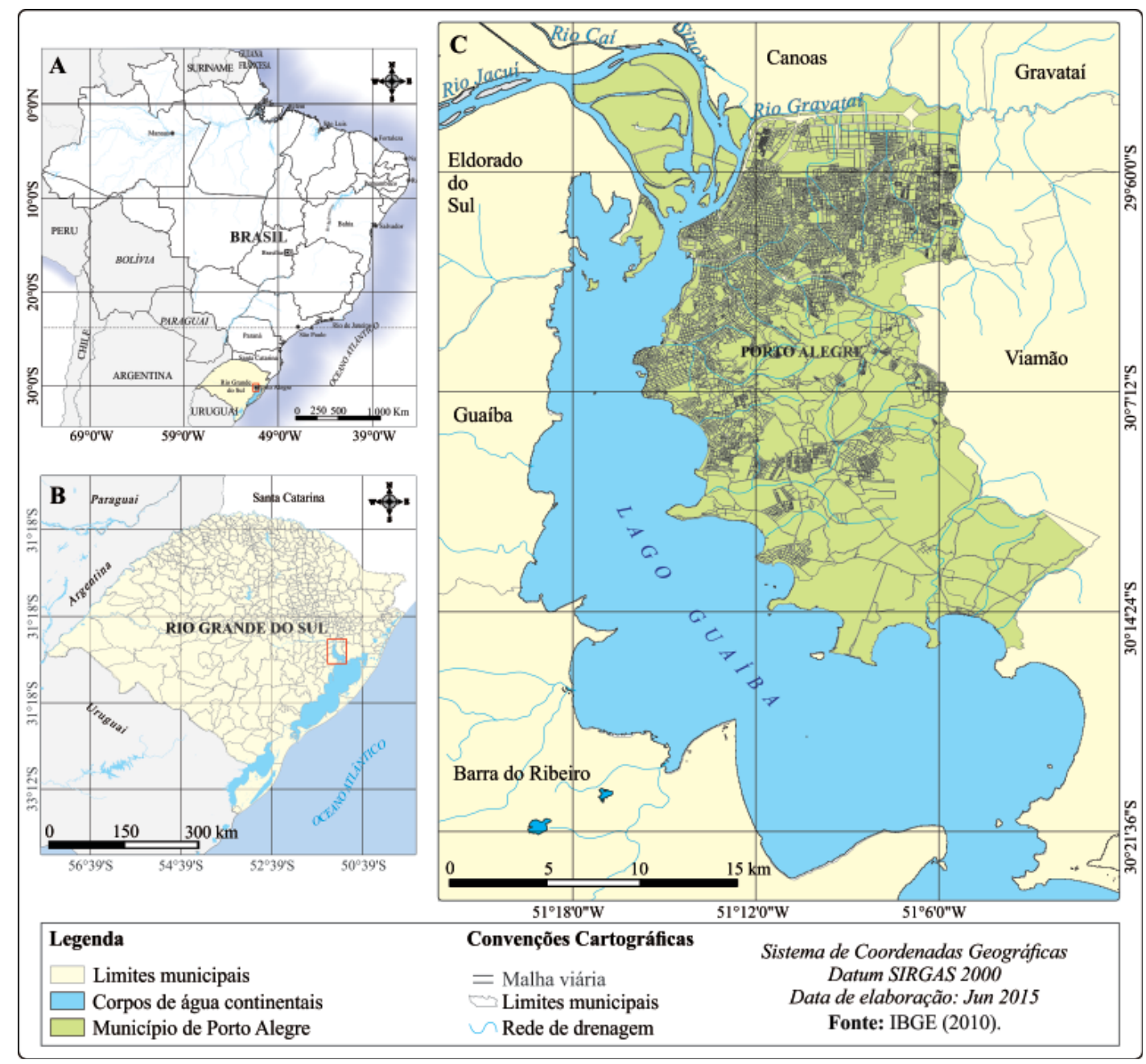

Figura 1. Mapa da área de estudo. A) Localização do Lago Guaíba no Brasil; B) Localização do Lago Guaíba no estado do Rio Grande do Sul; C) Lago Guaíba com destaque a capital Porto Alegre.

Figure 1. Map of the Study Area. A) Location of Guaíba Lake in Brazil; B) Location of Guaíba Lake in the state of Rio Grande do Sul; C) Guaíba Lake with highlight to the capital Porto Alegre. 


\subsection{Materiais}

Foram utilizados os seguintes materiais: (a) dados de precipitação da estação meteorológica do INMET (Instituto Nacional de Meteorologia) de Porto Alegre ( $\mathrm{n}^{\circ}$ da estação: 83967); (b) dados hiperespectrais obtidos com o espectrorradiômetro FieldSpec ${ }^{\circledR}$ HandHeld; (c) dados limnológicos coletados in situ: totais de sólidos em suspensão (TSS) em mg L ${ }^{-1}$, clorofila-a em $\mu \mathrm{g} . \mathrm{L}^{-1}$ e turbidez em NTU. E parâmetros como temperatura (da água e do ar), pH, condutividade elétrica, totais de sóli- dos dissolvidos e transparência da água (cm), para auxiliar na inferência dos parâmetros opticamente ativos e condições locais de tempo; e (d) imagem multiespectral do sensor LISS-III do satélite ResourceSat-2 (Quadro 1).

0 satélite Resourcesat- 2 conta com três câmeras imageadoras: LISS-III, LISS-IV e AWiFS, sendo que neste trabalho se utilizou a primeira. A imagem do sensor LISS-III/ResourceSat-2 do 08 de fevereiro de 2015 (Órbita/Ponto: 328/100) foi adquirida no catálogo de imagens do INPE (http:// www.dgi.inpe.br/CDSR/).

Quadro 1. Características do sensor LISS-III (modificado de NRSA, 2003).

Chart 1. LISS-III sensor characteristics (modified from NRSA, 2003).

\begin{tabular}{|c|c|c|c|}
\hline \multirow{4}{*}{ LISS-III } & Bandas & $\begin{array}{c}\text { Comprimento de } \\
\text { Onda (micrometros) }\end{array}$ & $\begin{array}{c}\text { Resolução } \\
\text { Espacial }\end{array}$ \\
\cline { 2 - 3 } & Band 2-Verde & $0.52-0.59$ & \multirow{2}{*}{$24 \mathrm{~m}$} \\
\cline { 2 - 3 } & Band 3- Vermelho & $0.62-0.68$ & \\
\cline { 2 - 3 } & Band 3 - Infravermelho Próximo & $0.77-0.86$ & \\
\cline { 2 - 3 } & Band 4 - SWIR & $1.55-1.70$ & \\
\cline { 2 - 3 } & Largura de faixa imageada: 142 km & \multicolumn{2}{|c|}{ Resolução radiométrica: 10 bits } \\
\hline
\end{tabular}

\subsection{Métodos}

Uma questão muito importante a ser considerada quando se trabalha com dados limnológicos é a sua representatividade espacial. Quando a representatividade espacial dos dados é bastante variável, fica difícil a comparação dos dados entre si. Além disso, a espacialização ou representatividade dos dados pode variar com o tamanho do sistema aquático. Quanto maior o corpo d'água maior a variabilidade dos fatores biológicos, abióticos e antrópicos (Novo \& Tundisi, 1988).

No caso do Lago Guaíba a necessidade de dados frequentes (mensais, por exemplo) por longo período de tempo inviabilizam, ou tornam muito difícil o aumento do número de estações de coleta. O Departamento Municipal de Água e Esgotos de Porto Alegre (DMAE), mais recentemente vem trabalhando com um reduzido número de estações de coleta mensais, e a amostragem vem sendo feita no decorrer de vários dias do mês, o que torna normalmente difícil sua análise integrada. Frente a estas limitações, o sensoriamento remoto tem se mostrado extremamente útil possibilitando, por meio de sua visão sinótica, ampliar a representatividade espacial das amostragens convencionais (Novo \& Tundisi, 1988).

A coleta de dados limnológicos e espectrais in situ foi planejada concomitante com a passagem do satélite. Foi realizada uma classificação das bandas 2, 3 e 4, do sensor OLI, utilizando um algoritmo de classificação supervisionado por regiões com base na distância Bhattacharya (Mather, 1999). Esse método de classificação requer conhecimento prévio do intérprete sobre o comportamento espectral dos alvos estudados (Oliveira \& Mataveli, 2013).

Para definição e distribuição das estações de coleta (ECs), foram identificadas nas imagens de satélite (sensor OLI) regiões heuristicamente definidas por compartimentos do lago em diferentes classes espectrais. Foram definidas 25 ECs, de forma a contemplar todo o Lago Guaíba, que foram utilizadas na campanha de campo realizada no dia 9 de fevereiro de 2015. Áreas marginais e de enseadas no Lago não foram consideras na amostragem dos dados, devido à baixa profundidade (entre 0,5 e $2,0 \mathrm{~m}$ ). 


\subsubsection{Coleta de dados espectrais e limnológicos}

Os dados hiperespectrais e limnológicos foram coletados no dia 09 de fevereiro de 2015, em 25 ECs no Guaíba (Figura 2). Para a coleta de dados hiperespectrais utilizou-se o espectrorradiômetro FieldSpec ${ }^{\circledR}$ HandHeld que possui faixa de sensibilidade entre 325 e $1075 \mathrm{~nm}$, nas faixas do visível e infravermelho próximo (ASD, 2003). A metodologia de coleta dos espectros de reflectância da água é descrita por Steffen et al. (1996). Desta forma, antes de qualquer coleta foi realizada a calibração, otimização do aparelho e a coleta da reflectância da placa Spectralon, sob condições mínimas de cobertura de nuvens.

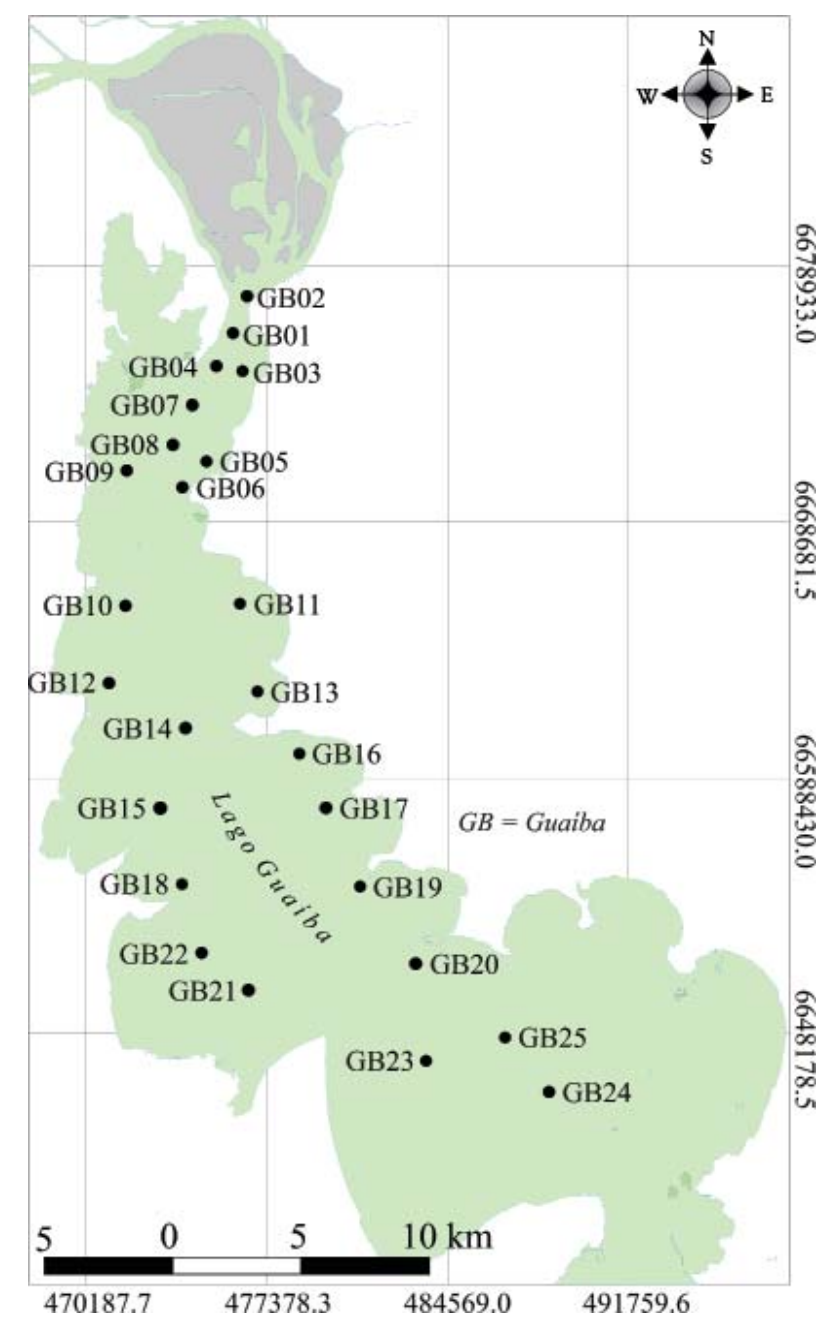

Figura 2. Localização das estações de coleta no Lago Guaíba. Figure 2. Location of sampling stations in the Lake Guaíba.

Os horários estabelecidos para coletas a campo foram entre $10 \mathrm{~h}$ e $15 \mathrm{~h}$ (horário local) para minimizar os efeitos de geometria de iluminação e visada do sensor, durante a aquisição dos dados. Para evitar a interferência do barco com a superfí- cie da água e a influência da radiação solar direta, o instrumento foi posicionado sobre cada estação amostral, com ângulo $\varphi_{\mathrm{v}}$ de $90^{\circ}$ - $135^{\circ}$ com o plano de radiação incidente, e $\theta_{v}$ de 30 a $45^{\circ}$ de inclinação do sensor em relação a vertical (Tang et al., 2004). Desta forma, evitou-se que o ângulo de visada do sensor e o ângulo zenital solar se mantivessem próximos para evitar, assim, a reflexão especular da superfície da água (efeito sunglint) (Bukata et al., 1995).

Cada espectro adquirido em campo consistiu na média de 10 leituras com o espectrorradiômetro, para todas as estações amostrais. Sobre esses espectros aplicou-se o filtro de média simples $(n=7)$ com o objetivo de suavizar e amenizar a presença de ruídos (Menezes \& Almeida, 2012).

As variáveis limnológicas Total de Sólidos em Suspensão (TSS) em mg $\cdot \mathrm{L}^{-1}$ e concentração de clorofila-a (Chl- $a$ ) em $\mu \mathrm{g} . \mathrm{L}^{-1}$ foram coletadas em sub-superfície (aproximadamente $30 \mathrm{~cm}$ ) com o auxílio de garrafas plásticas de $1 \mathrm{~L}$ para posterior análise em laboratório.

A determinação dos valores de TSS se deu conforme metodologia descrito por Wachholz (2011), onde foram utilizados filtros de celulose (Millipore - HAWG04700) constituídos por membranas $H A$ em ester de celulose com porosidade de 0,45 m e diâmetro de $47 \mathrm{~mm}$ (Millipore, 2013).

A clorofila-a foi determinada em laboratório segundo Yunes \& Araújo (s/d) com base em Paranhos (1996) e Chorus \& Bartram (1999). Para filtragem utilizou-se filtro de fibra de vidro, tipo Whatman GT/F (diâmetro $47 \mathrm{~mm}$ ). A concentração de clorofila-a é calculada com a fórmula do método proposto por Mackinney (1941), em que se considera a absorbância, medida em espectrofotômetro, nos comprimentos de onda de 663 e $750 \mathrm{~nm}$. A medida de turbidez foi realizada com o auxílio do equipamento multi-sensor Horiba U-10 (Horiba, 2014). A transparência da água foi medida de acordo com a profundidade do Disco de Secchi $(\mathrm{em} \mathrm{cm})$.

Levou-se em conta a região da coluna d'água eufótica, que corresponde a aproximadamente 2 a 3 vezes o limite de visibilidade indicado pelo disco de Secchi, podendo variar com a capacidade da água em atenuar a radiação subaquática (Carlson, 1977; Preisendorfer, 1986). 


\subsubsection{Processamento das imagens do sensor LISS -III/ResourceSat-2}

Como a imagem do sensor OLI do dia de coleta apresentou nuvens, o sensor LISS-III/ResourceSat-2 foi utilizado para analisar a resposta espectral em função dos constituintes opticamente ativos e estimar sua concentração e distribuição em todo o Lago Guaíba.

0 pré-processamento da imagem LISS-III envolveu as etapas de correção radiométrica (para remoção dos efeitos atmosféricos) e correção geométrica (registro). A calibração radiométrica e a correção dos efeitos da atmosfera são passos fundamentais no processo de correção radiométrica, para se obter valores de parâmetros físicos (radiância e reflectância) das imagens passíveis de serem interpretados espectralmente, comparados e com o mínimo de influência de gases da atmosfera (Markham \& Barker, 1986; Jensen, 2011).

Foi utilizada a correção atmosférica Fast Line-of-sight Atmospheric Analysis of Spectral Hypercubes (FLAASH) que exige a entrada de dados orbitais calibrados radiometricamente e que estejam em valores de radiância aparente $\left(\mathrm{mW} /\left(\mathrm{cm}^{-2} \mathrm{sr}^{-1} \mu \mathrm{m}^{-1}\right)\right.$. O FLAASH incorpora o código de transferência radioativa MODTRAN4 e requer parâmetros como: a latitude e longitude da cena, tipo de sensor, elevação média do terreno, data e horário de captura da cena e parâmetros para o modelo atmosférico (Anderson et al., 1999; Matthew et al., 2002). Após à execução do módulo, os valores de radiância aparente são transformados em reflectância de superíficie, tornam a imagem factível à processamentos e análises espectrais.

Para a imagem LISS-III obtida os parâmetros de latitude e longitude são: -29,75316 e -51,59228; Sensor LISS-III; elevação média do terreno: 821 Km; modelo atmosférico: Mid-Latitude Summer. 0 resultado final foi uma imagem em reflectância de superfície, utilizada para estimativa dos parâmetros limnológicos coletados em campo.

O processo de correção geométrica das imagens foi realizado com o método de registro de imagem, com base em cenas do sensor OLI/Landsat-8 da área de estudo.

\subsubsection{Análise derivativa e de correlação}

Utilizou-se a análise derivativa para detectar e realçar os efeitos dos constituintes opticamente ativos nos espectros de reflectância e relacionar a derivada da reflectância em relação ao comprimento de onda com a concentração de determinado constituinte, como sólidos em suspensão ou clorofila. A derivada dos dados espectrais realça o sinal nos comprimentos de onda em que ocorre as maiores oscilações (positivas e negativas) nos valores reflectância na presença de componentes oticamente ativos (Morrey, 1968). A primeira e a segunda derivada foram calculadas a partir dos 25 espectros de reflectância com filtro de média de 7 pontos (bandas) de forma a evitar que os ruídos fossem amplificados no processo de diferenciação (Tsai \& Philpot, 1998). Para a equação de derivada utilizou uma separação entre bandas de 3 nm (resolução) (Equação 1).

$$
\left.\frac{d s}{d \lambda}\right|_{i} \approx \frac{s\left(\lambda_{i}\right)-s\left(\lambda_{j}\right)}{\Delta \lambda} \quad \text { Equação } 1
$$

Onde, $\Delta \lambda$ é a separação entre bandas adjacentes $\Delta \lambda=\lambda_{\mathrm{j}}-\lambda_{\mathrm{i}}$ e $\lambda_{\mathrm{j}}>\lambda \mathrm{i}$ e o intervalo entre banda é assumido como constante. $s\left(\lambda_{n}\right)$ é o valor de reflectância na faixa de comprimento de onda $\lambda_{\mathrm{n}}$.

Para determinar se existe associação entre os dados hiperespectrais de reflectância e os resultantes do cálculo de derivada eles foram correlacionados com as variáveis limnológicas. Também foram utilizados para avaliar quais os comprimentos de onda estariam influenciando de forma mais significativa as variáveis TSS, Chl- $a$, transparência (profundidade do Disco de Secchi) e turbidez.

Para se avaliar a correlação foi utilizado o coeficiente de correlação de Pearson (r), aplicado para todos os comprimentos de onda. Este coeficiente pode variar entre -1 e +1 , sendo que, valores negativos de $r$ apontam para uma correlação inversa e os valores positivos para uma correlação direta (Callegari-Jacques, 2003). Foi realizado teste de hipótese que serve para avaliar a significância do coeficiente de correlação. Geralmente testa-se a hipótese nula de que a correlação na população é $\rho=0$, ou seja, não existe correlação, utilizando para isso a distribuição $t$. 


\section{Resultados}

Os dados limnológicos coletados no dia 09 de fevereiro de 2015 foram organizados e pré -avaliados por meio de estatísticas descritivas, permitindo uma visão da totalidade da variação e identificando, assim, possíveis valores inconsistentes (outliers). A tabela 1 permite constatar que os valores de sólidos em suspensão, clorofila-a e turbidez, componentes opticamente ativos considerados neste estudo, apresentam valores significativamente elevados quando comparados com os dados de campo obtidos por Corazza et al. (2013). Geralmente, em estudos semelhantes, autores procuram estimar os COAs em concentrações muito maiores do que os observados no Lago (Rundquist et al., 1996; Cheng et al., 2013).

A partir dos dados radiométricos foram obtidos os espectros de reflectância e de primeira derivada dos mesmos (Figura 3A e 3B, respectivamente). A baixa reflectância observada na faixa de comprimento de onda do azul em muitos casos é atribuída a presença de clorofila-a, matéria orgânica dissolvida e/ou húmus aquáticos que dependendo da concentração são responsáveis por elevar o coeficiente de absorção em direção aos comprimentos de onda mais curtos, mas com efeitos pouco notáveis (Gitelson, 1992; Dekker, 1993; Rudorff et al., 2007; Kirk, 2011).

Tabela 1. Estatísticas descritivas das variáveis limnológicas coletadas na campanha de campo em fevereiro de 2015, Lago Guaíba, RS.

Table 1. Descriptive statistics of the limnological variables collected in the field campaign in February 2015, Lake Guaíba, RS.

\begin{tabular}{lrrrrrrc}
\hline Variáveis & N & Mínimo & Máximo & Média & $\begin{array}{l}\text { Desvio } \\
\text { Padrão }\end{array}$ & Variância & Referência \\
\hline pH & 25 & 6,19 & 7,21 & 6,73 & 0,28 & 0,08 & 6,0 a 9,0 \\
CE $(\mu \mathrm{S} / \mathrm{cm})$ & 24 & 51,00 & 76,00 & 60,63 & 5,32 & 28,33 & - \\
TDS & 25 & 27,00 & 55,00 & 33,00 & 5,37 & 28,83 & - \\
TUR $(\mathrm{NTU})$ & 25 & 24,10 & 45,60 & 35,08 & 6,04 & 36,47 & $100 \mathrm{NTU}$ \\
TSS $\left(\mathrm{mg} / \mathbf{L}^{-\mathbf{1}}\right.$ ) & 25 & 4,00 & 24,00 & 12,53 & 5,59 & 31,30 & $500 \mathrm{mg} / \mathrm{L}^{-1}$ \\
Chl-a $\left(\mu \mathrm{\mu g} / \mathbf{L}^{-\mathbf{1}}\right)$ & 25 & 3,37 & 51,36 & 19,30 & 12,93 & 167,07 & $30 \mu \mathrm{\mu g} / \mathrm{L}^{-1}$ \\
Temperatura & 25 & 27,30 & 30,90 & 28,48 & 0,93 & 0,86 & - \\
água & & & & & & & \\
Temperatura Ar & 23 & 25,30 & 33,00 & 28,96 & 2,50 & 6,23 & - \\
Transparência & 25 & 40,00 & 78,00 & 56,96 & 11,00 & 120,96 & - \\
(cm) & & & & & & & - \\
Profundidade (m) & 25 & 0,91 & 12,19 & 3,90 & 2,58 & 6,64 & - \\
\hline
\end{tabular}

Obs.: Os valores de referência segundo a resolução CONAMA 357/2005 para classe II (águas que podem ser destinadas ao abastecimento humano, após tratamento; à proteção das comunidades aquáticas; à recreação de contato primário; à irrigação de hortaliças, plantas, parques e jardins, etc.; e à atividade de pesca).

Outras características observadas na reflectância espectral foram: o pico na região do verde, no transecto 1 (Figura 3A), em torno de 570 $\mathrm{nm}$, causado pela menor absorção pela clorofila-a. Também atribuída à presença de clorofila- $a$, está o decréscimo na quantidade de radiação refletida nos comprimentos de onda do azul (400 para $500 \mathrm{~nm}$ ) e do vermelho (675 a $680 \mathrm{~nm}$ ) (Gitelson, 1992; Jensen, 2011; Wang et al., 2017).

Parte das ECs apresentaram espectros com algumas distinções em relação as demais. Pontos com maiores concentrações de clorofila- $a$ em $\mu \mathrm{g}$ .L-1 (por exemplo: GB25 $(51,36)$, GB20 $(41,26)$,
GB12 $(37,05), \operatorname{GB} 18(29,47))$ apresentaram um declive, ou seja, uma diminuição acentuada na magnitude de reflectância em 620 e $680 \mathrm{~nm}$, transectos 2 e 4, respectivamente, da Figura 3A. Ambas as feições de absorção são descritas por Gitelson (1992) e Mattews et al. (2010) como associadas à absorção pela ficocianina e clorofila- $a$, respectivamente. As ECs com concentrações abaixo da média de clorofila- $a$ (GB01 (3,37), GB02 (8,42), GB07 (3,30), GB09 $(6,74)$ e GB11 7,58)) não apresentaram tais feições, principalmente em $680 \mathrm{~nm}$ (Figura 3A). 

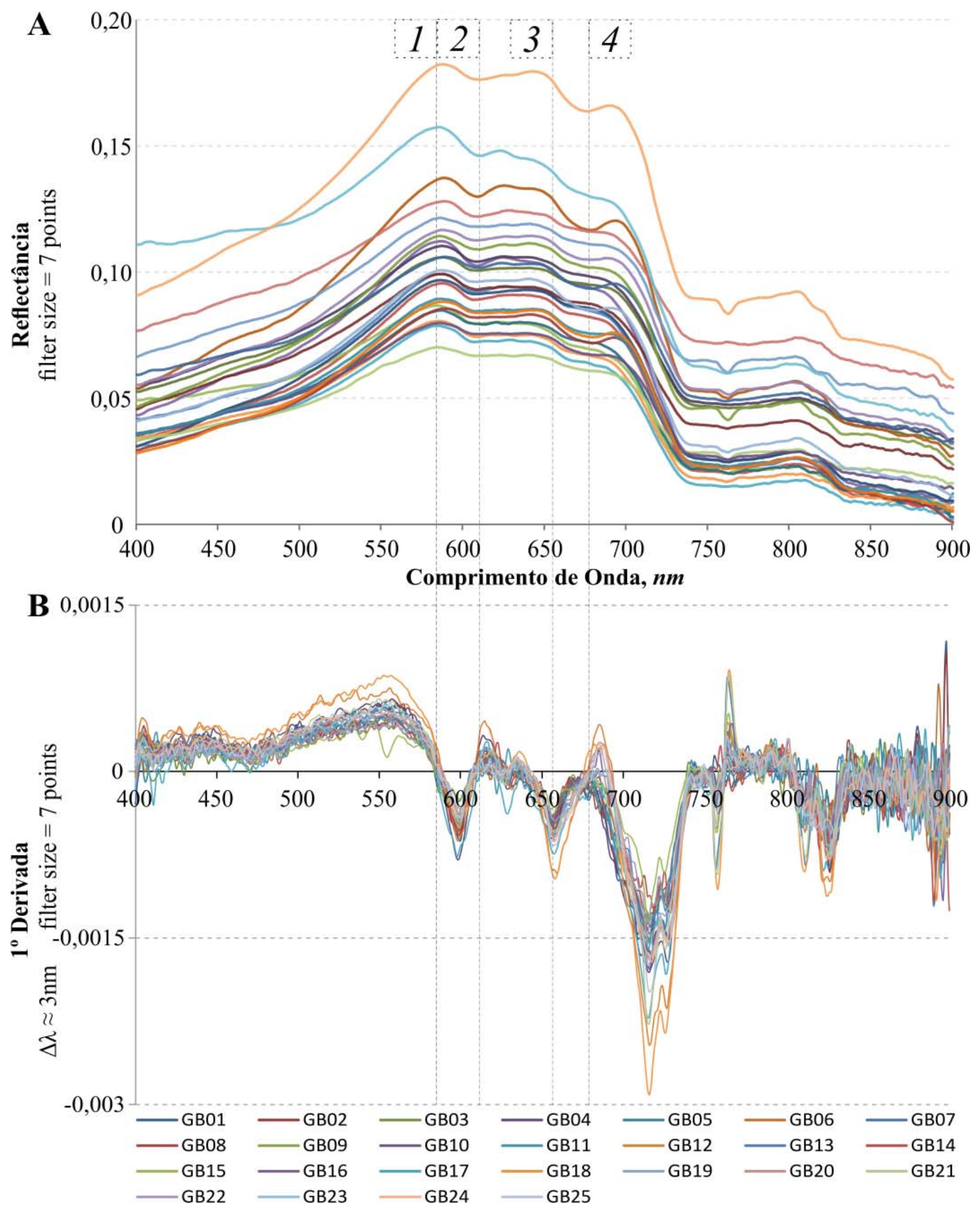

Figura 3. Espectros da água coletados em campo. A) Espectro de reflectância; B) Primeira derivada dos dados de reflectância. Figure 3. Water spectrum collected in field. A) Reflectance spectrum; B) First derivative of reflectance data.

As curvas espectrais podem mostrar ainda indícios da presença de Chl- $a$, principalmente nas amostras que apresentam a feição de absorção na região do transecto 3 (Figura $3 \mathrm{~A}$ ) mais acentuada (Rodrigues et al., 2016). A presença de Chl- $a$ não é somente evidenciada pelas feições de absorção como também pela menor diferença entre os va- lores de reflectância integrada entre 600-700 nm e 750-800 nm (Arraut et al., 2005), ou seja, maior proximidade entre o vermelho (absorvido pelos pigmentos) e o infravermelho (espalhado pela estrutura celular). A baixa concentração de Chl- $a$ fez com que a diferença de reflectância entre as regiões do vermelho e do infravermelho fosse maior, 
evidenciado nas amostras GB01, 02, 04, 07, e principalmente em GB08 e GB25.

Para as ECs GB10 $(24,0)$, GB18 $(23,3)$, GB24 $(18,67)$ e GB25 $(19,3)$, em que se verificou maiores quantidades de sólidos em suspensão, os picos de reflectância tenderam a se deslocar em direção a comprimentos de ondas um pouco maiores (587 e $588 \mathrm{~nm})$. Enquanto para GB05 $(4,0), \operatorname{GB} 06(5,3)$, GB07 $(8,7)$ e GB08 $(4,6)$, em que se verificou menores quantidades de TSS, os picos se concentraram em comprimentos de onda de 584 a $586 \mathrm{~nm}$.

Nas curvas de primeira derivada, calculadas a partir dos 25 espectros de reflectância em relação ao comprimento de onda, observa-se determinadas feições espectrais aparentemente não notadas nas curvas de reflectância que ficam realçadas e as constantes aditivas de radiação são minimizados (Chen et al., 1992; Goodin et al., 1993).

Na primeira derivada alguns picos de maiores reflectância (Figura 3B) passam a cruzar o eixo das abscissas, por exemplo, o pico em $589 \mathrm{~nm}$ (transecto 1), de maior reflectância no verde. As curvas obtidas para o Lago, mantêm um padrão semelhante das curvas de primeira derivada obtidas por Santos (2012) e mostram um padrão de picovale bem definidos na região entre 670 e $750 \mathrm{~nm}$, semelhante ao relatado por Goodin et al. (1993).
3.1 Regressões empíricas para inferência de variáveis limnológicas a partir da imagem do sensor LISS-III/ResourceSat-2

As bandas do sensor LISS-III/ResourceSat-2, do dia 8 de fevereiro de 2015 (um dia anterior ao dia de coleta de campo), cujos valores de reflectância apresentaram os melhores resultados de correlação com os dados de campo, foram utilizadas para estimar a distribuição espacial da turbidez (TUR) e da transparência no Lago Guaíba. 0 diagrama de dispersão entre os dados de reflectância na banda 3 do sensor LISS-III e de turbidez coletados em campo e a equação linear para estimativa da turbidez (modelo empírico) estão representados na figura 4. A análise resultou em um Coeficiente de Determinação $\mathrm{R}^{2}=0,753$ e coeficiente de correlação $r=0,868$. 0 coeficiente de correlação obtido foi testado via teste $\mathrm{t}$ de Student para $\alpha=0,05$ e $\mathrm{n}=$ 25 - 2 graus de liberdade.

Para a transparência da água, a banda 3 do sensor LISS-III apresentou boas correlações com a reflectância. A figura 5 apresenta o diagrama de dispersão entre os dados de reflectância (banda 3) e de transparência e a equação linear para estimativa da transparência, com coeficiente de determinação $R^{2}=0,827$ e coeficiente de correlação $r=-0,909$.
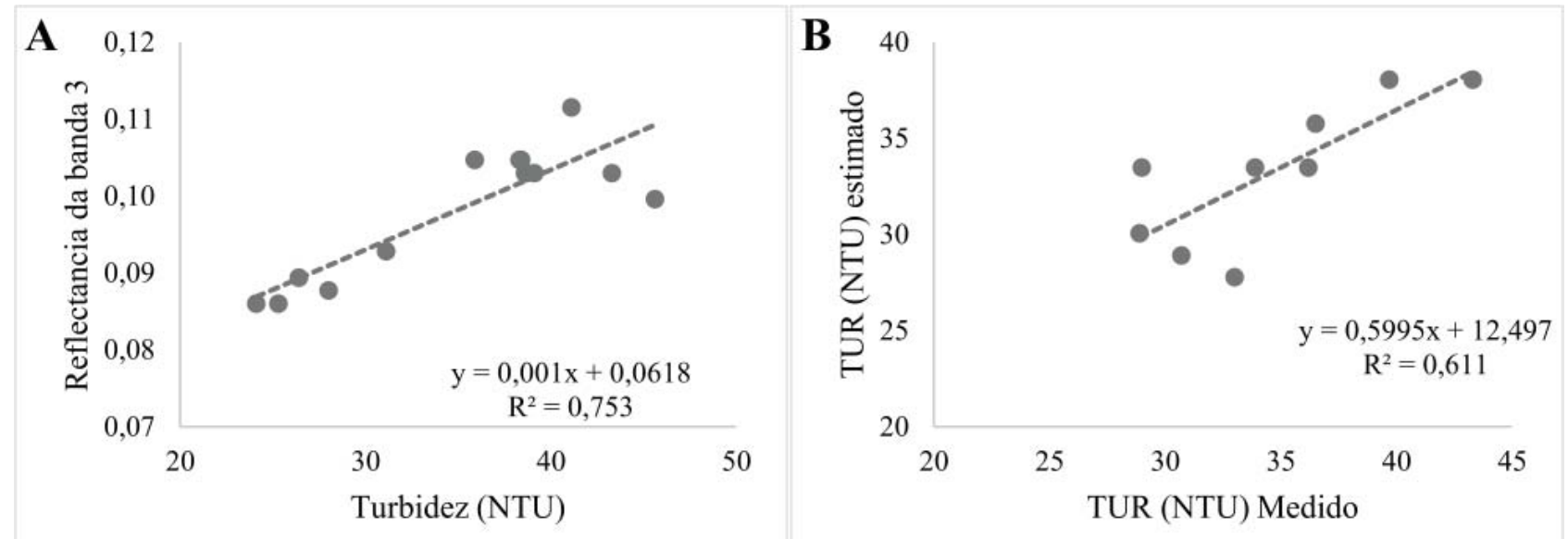

Figura 4. Diagramas de dispersão com regressões empíricas utilizadas para estimativa e validação dos dados. A) Modelo linear empírico para estimativa da turbidez, em 8 de fev. de 2015, a partir de dados de reflectância da banda 3 do sensor LISS-3; B) Teste de validação do modelo.

Figure 4. Scatter plot with empirical regressions used for data estimation and validation. A) Empirical linear model for turbidity estimation, on February 8, 2015, based on the reflectance data of the LISS-3 sensor (band 3); and B) Validation test of the model. 

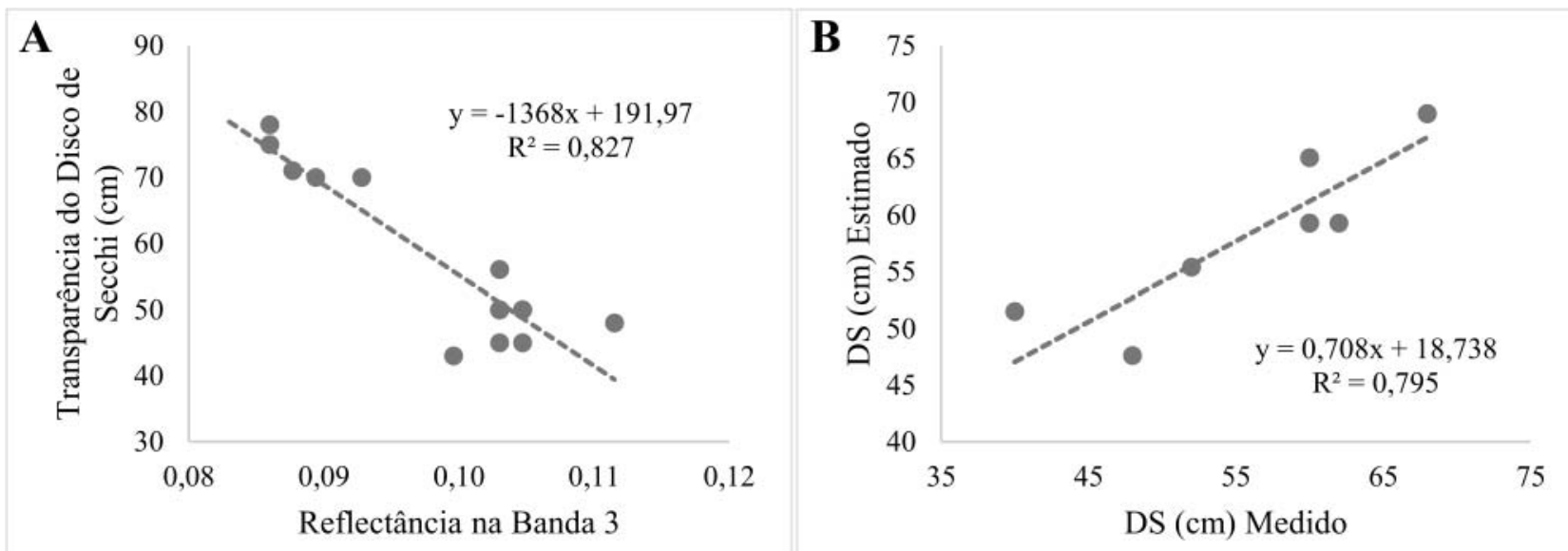

Figura 5. Diagramas de dispersão com regressões empíricas utilizadas para estimativa e validação dos dados. A) Modelo linear empírico para estimativa da transparência, em 8 de fev. de 2015, a partir de dados de reflectância da banda 3 do sensor LISS-3; B) Teste de validação do modelo.

Figure 5. Scatter plot with empirical regressions used for data estimation and validation. A) Empirical linear model for transparency estimation, on February 8, 2015, based on the reflectance data of the LISS-3 sensor (band 3); and B) Validation test of the model.

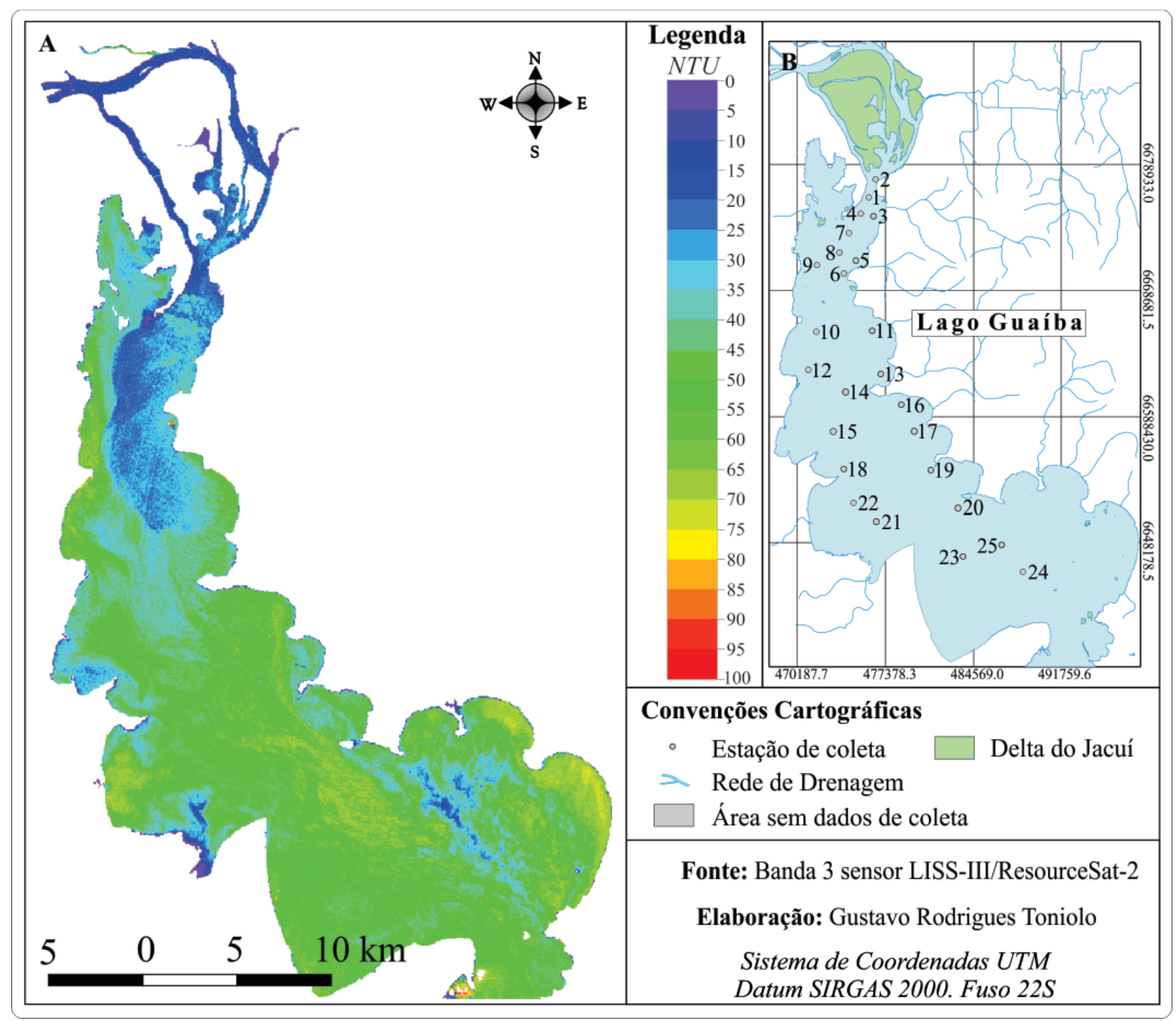

Figura 6. Mapa representando as variações nos valores de turbidez estimada, em NTU. A) Turbidez estimada a partir da banda 3 do sensor LISS-III, 8 de fevereiro de 2015, Lago Guaíba - RS; B) Localização das estações de coleta.

Figure 6. Map representing the variations in estimated turbidity values, in NTU. A) Estimated turbidity from LISS-III sensor band 3, February 8, 2015, Lago Guaíba - RS; B) Location of sampling stations. 
A partir da validação, os modelos (Figuras 4 e 5) foram aplicados sobre a imagem da banda 3 do Sensor LISS-III, buscando analisar a distribuição espacial das variáveis limnológicas estimadas.

Os resultados obtidos da aplicação dos modelos empíricos para estimar a turbidez e transparência na água do Lago Guaíba estão apresentados nas figuras 6 e 7. Os menores valores de turbidez foram encontrados na área associada ao deságue da Região Hidrográfica do Guaíba, logo após o delta do Jacuí, com valores entre 28 e 30 NTU. Já os maiores valores se encontram no setor central e sul do Lago, entre 44 e 50 NTU.

Sendo a turbidez a medida da dificuldade de um feixe de luz atravessar certa quantidade de água, a transparência está estritamente relacionada com a mesma. Desta forma, o modelo de estimativa da transparência também resultou em bom desempenho (Figura 7). A classificação da distribuição espacial dos valores de transparência evidenciou diferentes compartimentos aquáticos no Lago.

A baixa transparência da água é acompanhada pelo aumento da concentração de sólidos em suspensão (Smith et al., 2014). Observa-se que em setores do Lago onde ocorrem as menores velocidades de escoamento (Paz et al., 2005), e onde há precipitação do material particulado em suspensão, tem-se menor disponibilidade de luz, refletindo em valores baixos de transparência (Corazza et al., 2013).

Os maiores valores de transparências da água foram verificados no compartimento norte do Lago, e próximo a ponta do Itapuã ao Sul, com

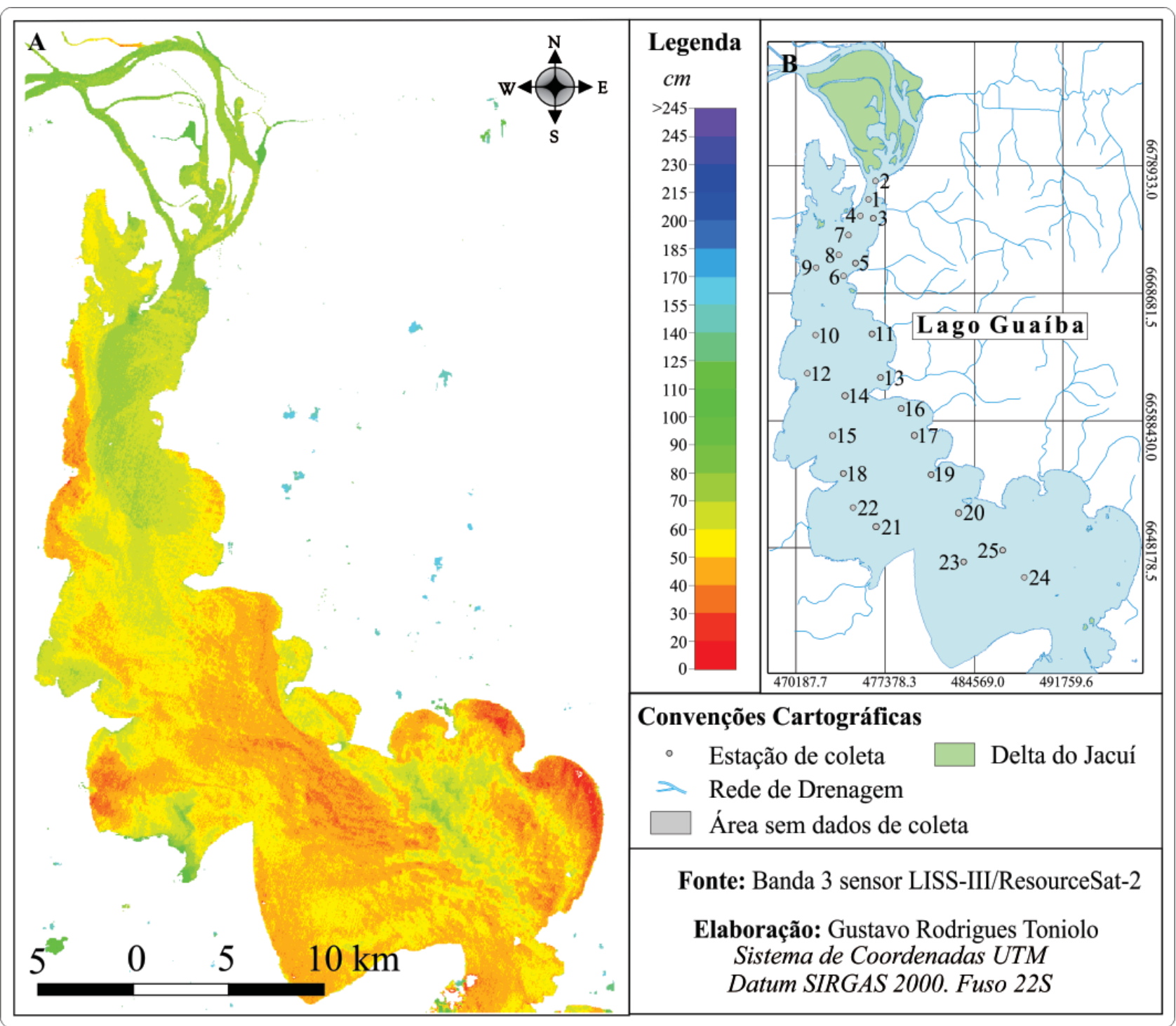

Figura 7. Mapa representando as variações nos valores de transparência estimada, em cm. A) Transparência estimada a partir da banda 3 do sensor LISS-III, 8 de fevereiro de 2015, Lago Guaíba - RS; B) Localização das estações de coleta Figure 7. Map representing the variations in estimated transparency values, in NTU. A) Estimated transparency from LISS-III sensor band 3, February 8, 2015, Lago Guaíba - RS; B) Location of sampling stations. 
transparência chegando a $80 \mathrm{~cm}$, ou seja, o modelo gerou valores superestimados já que a transparência máxima verificada no período foi de $78 \mathrm{~cm}$. Já os menores valores são encontrados no compartimento central e ao sul do Lago, entre 20 a $30 \mathrm{~cm}$.

\section{Discussão dos resultados}

Os resultados obtidos dos espectros coletados em campo demonstram que o aumento da reflectância em toda a faixa espectral está relacionado quase que diretamente às diferentes concentrações de sólidos, principalmente a faixa de comprimento de onda do infravermelho de 700 a 850 $\mathrm{nm}$. Desta maneira as maiores concentrações de sólido em suspensão (mg. $\left.\mathrm{L}^{-1}\right)$ podem proporcionar maiores reflectâncias (Chen et al., 1992; Wu et al., 2014; Wang et al., 2017).

Com relação a análise derivativa Rudorff et al. (2007), Wu et al. (2014) e Wang \& Tian (2015) destacam que os dados hiperespectrais são muito sensíveis às componentes que causam variações na radiância detectada pelo sensor, e a aplicação de tal técnica tem como vantagem minimizar os efeitos causados por tais componentes e destacar as feições de absorção ou espalhamento que estão ligadas principalmente a presença em baixa concentração dos COAs.

Os resultados mostram que a primeira derivada espectral apresentou formas relativamente similares em comprimentos de onda mais curtos, entre 400 e $500 \mathrm{~nm}$, variando pouco. Conforme aumentou-se o comprimento de onda os picos de absorção e reflectância nas curvas de derivada correspondem às feições de maiores inclinações nos espectros de reflectância. Evidenciou-se, desta forma, os pontos onde se encontram as mudanças bruscas de resposta espectral. A partir de 500 até aproximadamente $590 \mathrm{~nm}$, verificou-se uma mudança associada ao pico de reflectância no verde, tais resultados assemelham-se aos encontrados por Corazza (2010).

Além disso, embora os espectros originais adquiridos em campo difiram em magnitude, no intervalo de 400 a $900 \mathrm{~nm}$, eles têm valores muito próximos na primeira derivada, mesmo que em alguns intervalos de comprimento de onda ainda se possa visualizar diferenças na magnitude dos valores. As mudanças, até as mais sutis, na curvatura que são consistentes ao longo de todo intervalo, aparecem nos espectros derivados, tanto como mudanças positivas como negativas. As mesmas observações também foram feitas por Tsai \& Philpot (1998).

4.1 Correlação dos dados de reflectância com as variáveis limnológicas

A figura 8 apresenta o correlograma gerado entre os espectros de reflectância obtidos em campo e as variáveis limnológicas opticamente ativas. Observa-se que entre os comprimentos de onda mais curtos ( 400 e $500 \mathrm{~nm}$ ) a intensidade de correlação foi baixa entre todas as variáveis. Para a variável TSS as correlações mais altas foram encontradas entre os comprimentos de onda de 630 a $660 \mathrm{~nm}, r$ acima de 0,43 (ou $r^{2}=0,18$, ou seja, $18 \%$ da variação observada na reflectância é explicada pelas quantidades de TSS), e entre 685 a 730 $\mathrm{nm}, r$ máximo de 0,48 (ou $r^{2}=0,23$, ou seja, $23 \%$ da variação pode ser explicada). Embora o coeficiente de correlação seja significativo, há possibilidade de que as baixas concentrações de sólidos e clorofila não tenham sido suficientes para determinar feições típicas no espectro de reflectância, resultando em baixos coeficientes de correlação.

Para a variável TUR as correlações mais altas também foram encontradas entre os comprimentos de 685 a $730 \mathrm{~nm}$, com $r$ máximo de 0,56 em 709 nm (31\% da variação observada na reflectância é explicada pelas quantidades de TUR). Os dados de clorofila-a apresentaram fraca correlação e o DS apresentou correlação negativa entre a reflectância da água em todos os comprimentos de onda.

A análise do correlograma permite constatar que o TSS é a variável que domina a resposta espectral da água do Lago. Os valores de Chl- $a$ determinam feições nos espectros de reflectância (Rundquist et al., 1996; Mattews et al., 2010; Fan, 2014), entretanto, os baixos valores observados em alguns pontos resultaram em correlações pouco significativas com os espectros de reflectância da água.

A figura 9 apresenta o correlograma entre a primeira derivada e Totais de Sólidos em Suspensão, Transparência, Turbidez e Clorofila-a obtidos 


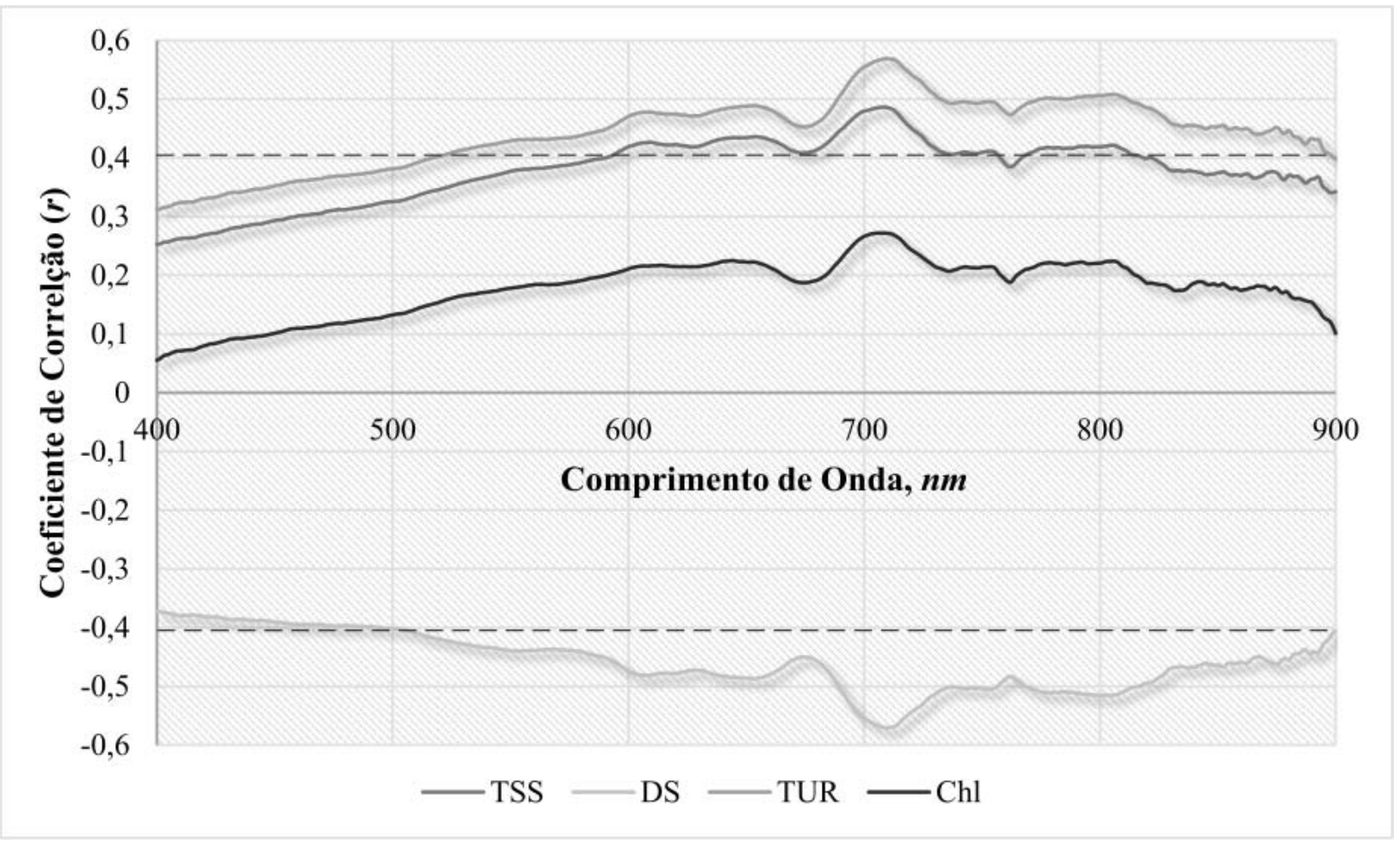

Figura 8. Correlograma entre as variáveis limnológicas com valores de reflectância nos diferentes comprimentos de onda. A linha tracejada indica o limite dos valores estatisticamente significativos $(\alpha=0,05)$.

Figure 8. Correlogram between limnologic variables with reflectance values at different wavelengths. Dashed line indicates the limit of statistically significant values $(\alpha=0,05)$.

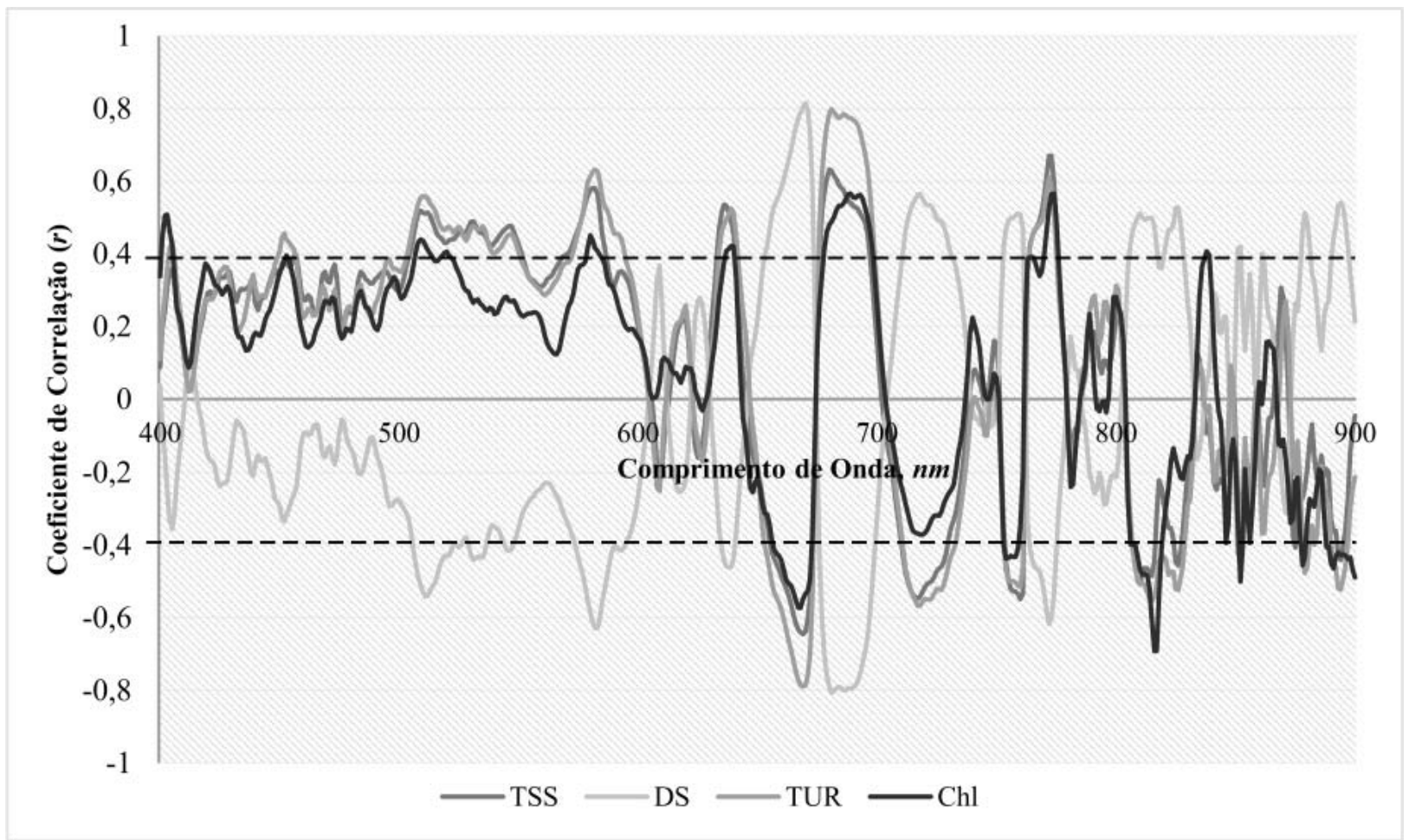

Figura 9. Correlação entre as variáveis limnológicas e a primeira derivada nos diferentes comprimentos de onda. Figure 9. Correlation between the limnological variables and the first derivative at the different wavelengths. 
na coleta de fevereiro de 2015. As linhas de correlação de TSS e TUR se assemelharam muito, apesar de que a TUR apresentou maiores valores de correlação positiva entre as faixas de 675 a $700 \mathrm{~nm}(r$ $=0,79)$ e negativa em $670 \mathrm{~nm}(r=-0,78)$.

As faixas que apresentaram maiores correlações com a primeira derivada foram: $584 \mathrm{~nm}(r=$ $0,60)$ com TSS e TUR e DS; 653-674 nm $(r=0,81)$ com DS; 655-674 e 675-700 nm com TSS, TUR e Chl- $a$; 710-733 nm com TUR e TSS; e $870 \mathrm{~nm}(r$ $=-0,69)$ com Chl- $a$. Sendo os valores significativos para $r$ acima de 0,39, de um nível de significância $\alpha=0,05$. A figura 10 apresentada os diagramas de dispersão e melhores ajustes das variáveis DS e TUR com a primeira derivada no comprimento de onda de $670 \mathrm{~nm}$.

Para a variável TSS a maioria dos picos positivos e negativos observados ficaram dentro do limite estatisticamente significativo para a primeira derivada, ou seja, $r$ superiores a 0,39 . Os maiores valores de $r$ para totais de sólidos em suspensão ocorreram a $680 \mathrm{~nm}(-0,63), 669 \mathrm{~nm}(-0,64)$ e 772 nm $(0,66)$, ou seja, no intervalo de comprimento de onda do vermelho e infravermelho próximo. As maiores diferenças entre o vermelho e infravermelho próximo são melhores explicadas pela presença de sedimentos em suspensão e turbidez. A figura 11 apresenta o diagrama de dispersão e o melhor ajuste para variável TSS com a primeira derivada no comprimento de onda de $772 \mathrm{~nm}$.

A inferência da variável limnológica turbidez, a partir de regressões empíricas, possibilitou a classificação da distribuição espacial dos valores desta variável, evidenciando diferentes compartimentos aquáticos relacionados aos diferentes valores de reflectância na água. Destaca-se que as maiores reflectâncias na região do vermelho estão associadas à presença de maiores valores de turbidez, o que por sua vez pode estar ligado ao volume de material orgânico e inorgânico (Volpe et al., 2011; Martinez et al., 2015).

Em geral, os algoritmos usados para a estimativa da variação espacial das variáveis por meio das imagens do sensor LISS-3 são constituídos com base nos dados de verdade de campo, sendo funcionais apenas dentro das datas estabelecidas. Observa-se também que os modelos empíricos funcionam bem dentro dos limites observados nos locais onde houve amostragem de campo. Para reflectâncias menores ou maiores do que os pontos amostrais, o modelo empírico tende a errar mais.

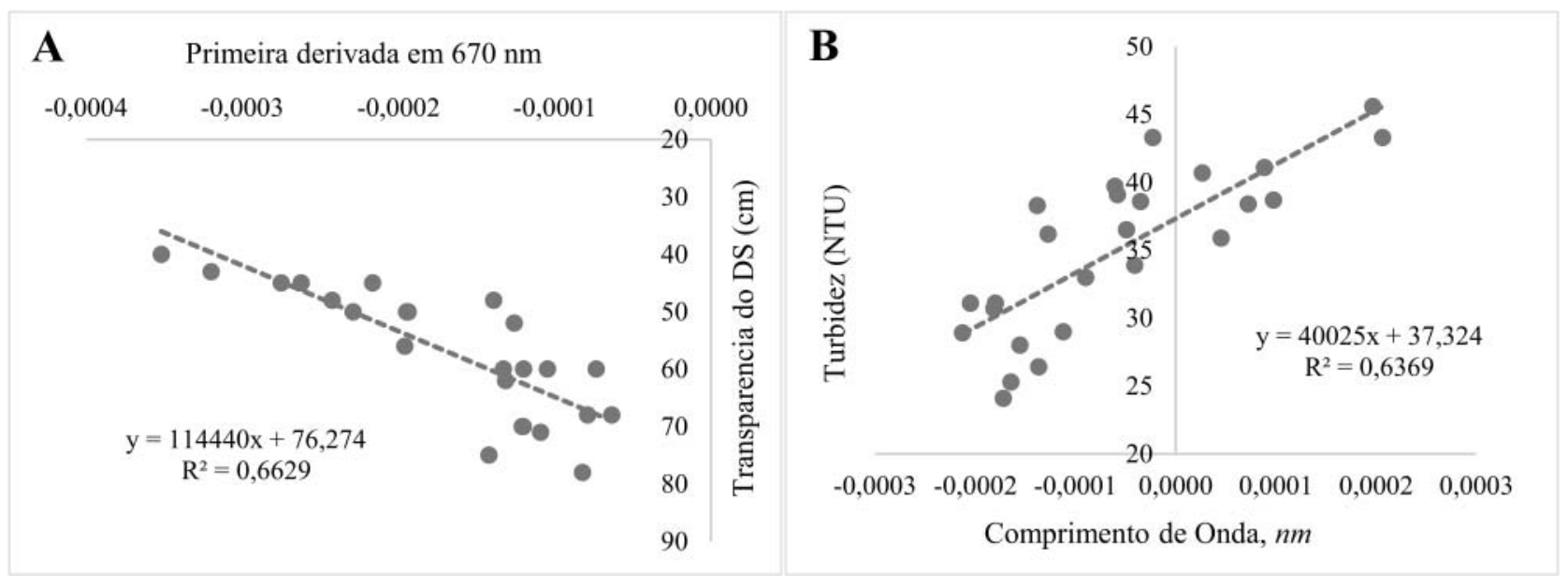

Figura 10. Modelos de regressão linear obtidos considerando o melhor ajuste de dados limnológicos com a primeira derivada da reflectância. A) Dados de transparência com primeira derivada em 670 nm; B) Dados de turbidez com primeira derivada em $670 \mathrm{~nm}$.

Figure 10. Linear regression models obtained considering the best fit of limnological data with the first derivative of reflectance. A) Transparency data with first derivative at $670 \mathrm{~nm}$; B) Turbidity data with first derivative at $670 \mathrm{~nm}$. 


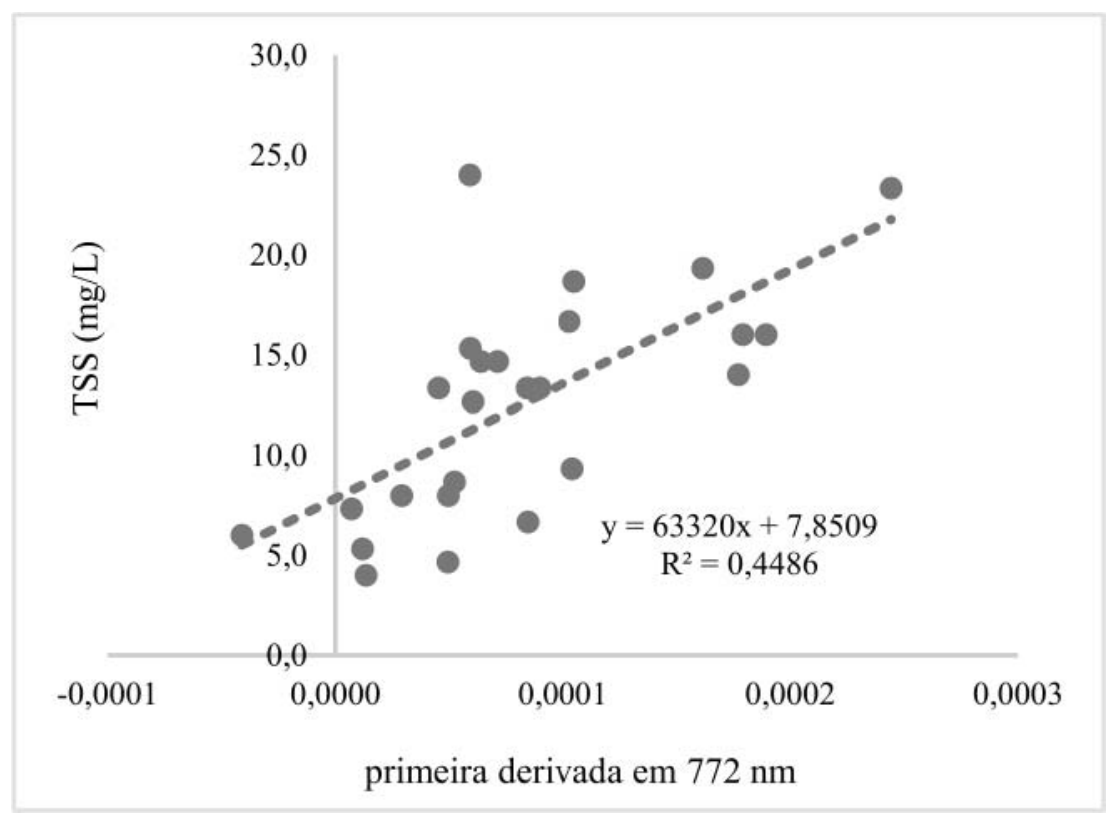

Figura 11. Diagrama de dispersão entre a variável TSS e a primeira derivada em $772 \mathrm{~nm}$. Figure 11. Scatter plot between the TSS variable and first derivative at $772 \mathrm{~nm}$

\section{Conclusões}

Os resultados obtidos corroboram as hipóteses levantadas inicialmente de que os dados espectrais obtidos por sensoriamento remoto são capazes de identificar a presença e discriminar a contribuição de cada constituinte opticamente ativo presente no Lago Guaíba.

O objetivo geral estabelecido para esta pesquisa somente foi atingido com a integração dos dados coletados de natureza limnológica e espectral. 0 Guaíba pode ser caracterizado como um lago interior tipicamente turvo e opticamente complexo, em que os sólidos em suspensão determinaram o seu comportamento espectral.

A análise visual dos espectros obtidos no dia 09 de fevereiro de 2015 e sua comparação com espectros da literatura (Rundquist et al., 1996; Lodhi et al., 1997; Ennes, 2008; Kirk, 2011; Corazza, 2015) sugere que a água do Lago tem presença de sólidos e clorofila-a. Sendo assim, a radiação ao penetrar a camada mais superior do corpo d'água foi espalhada principalmente por sólidos, aumentando a magnitude da reflectância, e absorvida em certas faixas de comprimentos de onda pela clorofila-a, definindo feições características.

A análise derivativa mostrou-se eficiente para realçar as feições nos espectros, tanto na pri- meira como segunda derivação. Sendo assim, algumas feições que não eram muito evidentes foram salientadas após a primeira derivação. 0 aumento das correlações após a derivação comprova que esta técnica aumenta o contrate espectral e a precisão das estimativas, conforme preconizado por Goodin et al. (1993).

Dentre as correlações significativas entre a primeira derivada, e variáveis limnológicas, no dia 09 de fevereiro de 2015, destacam-se as faixas de $584 \mathrm{~nm}(r=0,60)$ com TSS e TUR e DS; 653-674 $\mathrm{nm}(r=0,81)$ com DS; 655-674 e 675-700 nm com TSS, TUR e Chl- $a$; 710-733 nm com TUR e TSS; e $870 \mathrm{~nm}(r=-0,69)$ com Chl- $a$.

A primeira derivada em $772 \mathrm{~nm}$ explicou 44\% da variação devido ao TSS. Já em 690 nm, a primeira derivada explicou $32 \%$ da variação na concentração de clorofila-a, resultado semelhante ao encontrados por Rundquist et al. (1996). Os melhores resultados foram observados nas variáveis TUR e DS. Em $670 \mathrm{~nm}$ a primeira derivada explicou $66 \%$ da variação para turbidez. A partir destes resultados pode-se concluir que os baixos valores de clorofila- $a$ não são suficientes para determinar a resposta nos comprimentos de onda especificados, sendo determinada pela presença de sólidos na água.

Este trabalho mostrou um uso potencial 
das imagens do sensor LISS-III/ResourceSat-2 em estimar alguns parâmetros de qualidade da água no Lago Guaíba. Utilizando regressões lineares foi possível estimar os parâmetros de turbidez e profundidade do Disco de Secchi (transparência).

Os ajustes das regressões entre os dados LISS-III e as concentrações de totais de sólidos em suspensão e de clorofila-a não deram bons resultados, mesmo para ajustes não lineares.

Os dados limnológicos coletados em campo podem indicar que o Lago Guaíba apresenta água bastante túrbida, com concentração de sedimentos em suspensão e de clorofila-a elevados quando comparados a estudos na mesma área realizados por Corazza (2015). Os dados e sensoriamento remoto como fonte adicional de informações sobre o ecossistema aquático do Lago Guaíba, são de extrema utilidade.

Agradecimentos. À Coordenação de Aperfeiçoamento de Pessoal de Nível Superior (CAPES) pelo auxílio e bolsa de mestrado de Gustavo Rodrigues Toniolo. Ao Conselho de Desenvolvimento Científico e Tecnológico (CNPq) (Projeto 312081/20138). Aos colegas Felipe Correa e Alice Fassoni pelo apoio logístico em campo. Este trabalho é parte da Dissertação de Mestrado do primeiro autor junto ao Programa de Pós-graduação em Sensoriamento Remoto da UFRGS.

\section{Referências bibliográficas}

Anderson, G.P., Pukall, B., Allred, C.L., Jeong, L.S., Hoke, M., Chetwynd, J.H., Adlergolden, S.M., Berk, A., Berstein, L.S., Richtsmeier, S.C., Acharya, P.K. \& Matthew, M.W. 1999. FLAASH and MODTRAN4: state-of-the-art atmospheric correction for hyperspectral data. In: AEROSPACE CONFERENCE, 1999, Aspen. Proceedings... Aspen, IEEE, v. 5, p. 177-181.

Andrade Neto, J.S., Rigon, L.T., Toldo Jr., E.E. \& Chettini, F. 2012. Descarga Sólida em Suspensão do Sistema Fluvial do Guaíba, RS, e sua Variabilidade Temporal. Pesquisas em Geociências, 39(2): 161-171.

Arraut, E.M., Rudorff, C.M., Barbosa, C.C.F., Carvalho, J.C., Pereira Filho, W. \& Novo, E. M. L. M. 2005. Estudo do comportamento espectral da clorofila e dos sólidos em suspensão nas águas do Lago Grande de Curuai (Pará), na época da seca, através de técnicas de espectroscopia de campo. In: SIMPÓSIO BRASILEIRO DE SENSORIAMENTO REMOTO, 12., 2005, Goiânia. Anais... Goiânia, SBSR, p. 2447-2454.

ASD. Analytical Spectral Devices, Inc. 2003. FildSpec HandHeld Spectroradiometer: User's Guide. Revision C. Boulder, ASD Inc. Disponível em: <http://support.asdi.com/Document/ Documents.aspx $>$. Acesso em 14 de out. de 2014.

Bendati, M.M., Kirchheim, R.E. 1998. Lagos, rios e arroios: as doces águas da superfície. In: Menegat, R., Porto, M.L., Carraro, C.C., Fernandes, L.A.D. (Ed.). Atlas Ambiental de Porto Alegre. Porto Alegre, Universidade Federal do Rio Grande do Sul, p. 35-42.

Brochado, G.T. \& Macarringue, L.S. 2014. Uso de imagens do LISS-3/Resourcesat-1 e do OLI/ Landsat-8 no estudo espacial da queda do nível de água no lago de Furnas no ano de 2012. Revista Ambiente \& Água, 9(4): 664-678.

Bukata, R.P., Jerome, J.H., Kondratyev, A.S. \& Pozdnyakov, D.V. 1995. Optical Properties and Remote Sensing of Inland and Coastal Waters. CRC Press. 384p.

Callegari-Jacques, S.M. 2003. Bioestatística: princípios e aplicações. Porto Alegre, Artmed, 255p.

Carlson, R.T. 1977. A trophic state index for lakes. Limnologia and Oceanography, 22(2): 361-369.

Chen, Z., Curran, P.J. \& Hanson, J.D. 1992. Derivative reflectance spectroscopy to estimate suspended sediment concentration. Remote Sensing Environment, 40(1): 67-77.

Cheng, C., Wei, Y., Sun, X., \& Zhou, Y. 2013. Estimation of chlorophyll-a concentration in turbid lake using spectral smoothing and derivative analysis. International Journal of Environmental Research and Public Health, 10: 2979-2994.

Chorus, I. \& Bartram, J. 1999. Water Resources. In: Chorus, I. \& Bartram, J. (Eds). Toxic Cyanobacteria in Water: A guide to their Public Health Consequences, Monitoring and Management. New York, E \& FN Spon, p. 13-16.

Corazza, R. 2010. Relação entre Variáveis Espectrais e Limnológicas no Reservatório da Usina Hidrelétrica Dona Francisca-RS. Santa Maria, 
103p. Dissertação de mestrado, Programa de Pós-Graduação em Geografia, Centro de Ciências Naturais e Exatas, Universidade Federal de Santa Maria.

Corazza, R., Pereira Filho, W. \& Basso, L.A. 2013. Influência da precipitação pluviométrica nas características espectrais e limnológicas do reservatório Dona Francisca e do Lago Guaíba, Rio Grande do Sul. Para Onde!?, 7(2): 01-11.

Corazza, R. 2015. Identificação de Florações de Algas no Lago Guaíba com Uso de Imagens de Satélite e Espectrorradiometria de Campo. Porto Alegre, 226p. Tese de Doutorado, Programa de Pós-Graduação em Geografia, Instituto de Geociências, Universidade Federal do Rio Grande do Sul.

Dekker, A.G. 1993. Detection of Optical Water Quality Parameters for Eutrophic Water by High Resolution Remote Sensing. Journal of Chemical Information and Modeling, 53(9): 1689-1699.

Ennes, J. 2008. Potencial das imagens hiperespectrais orbitais na detecção de componentes opticamente ativos no reservatório de Itupararanga. Presidente Prudente, 125p. Dissertação de Mestrado, Programa de Pós-Graduação em Ciências Cartográficas, Universidade Estadual Paulista.

Fan, C. 2014. Spectral analysis of water reflectance for hiperspectral remote sensing of water quality in Estuarine Water. Journal of Geoscience and Environment Protection, 2:19-27.

Felix, I.M. 1993. Monitoramento da Qualidade da Água Utilizando-se Modelos Empíricos Obtidos a partir de Dados de Sensoriamento Remoto de Barra Bonita-SP. In: SIMPÓSIO BRASILEIRO DE SENSORIAMENTO REMOTO, 7., 1993, Curitiba. Anais...Curitiba, SBSR, p. 119-127.

FEPAM. Fundação Estadual de Proteção Ambiental Henrique Luiz Roesseler. 2015. Região Hidrográfica do Guaíba - Qualidade ambiental. Disponível em: < http://www.fepam.rs.gov.br/ qualidade/qualidade_jacui/jacui.asp $>$. Acesso em: 16 mai. 2015.

Gitelson, A. 1992. The Peak near 700 nm on Radiance Spectra of Algae and Water: relationships of its magnitude and position with chlorophyll concentration. International Journal of Remote Sensing, 13(17): 3367-3373.

Goodin, D.G., Han, L., Fraser, R.N., Rundquist, D.C.
\& Stebbins, W.A. 1993. Analysis of suspended solids in water using remotely sensed high resolution derivative spectra. Photogrammetric Engineering \& Remote Sensing, 59(4): 505-510. Horiba. 2014. Multi-parameter Water Quality Meters: U-50 Series. Horiba Process \& Environmental. Disponível em: <www.horiba.com/ fileadmin/uploads/Process-Environmental/ Documents/HRE1930C-U50.pdf>. Acesso em: 23 set. 2014.

IBGE. Instituto Brasileiro de Geografia e Estatística. 2010. Censo Demográfico 2010 - Resultados do Universo. Disponível em: <http://www. ibge.gov.br/home/estatistica/populacao/censo2010/default_resultados_universo.shtm>. Acesso em: 25 nov. 2014.

Jensen, J.R. 2011. Sensoriamento remoto do ambiente: uma perspectiva em recursos terrestres. Tradução José Carlos Epiphanio (coordenador) et al. $2^{\underline{a}}$ ed.. São José dos Campos, Parêntese, $600 \mathrm{p}$.

Jobim, G.S. 2012. Dispersão de poluentes: simulação numérica do Lago Guaíba. Porto Alegre, 67p. Monografia de conclusão de Curso, Curso de Engenharia Civil, Escola de Engenharia, Universidade Federal do Rio Grande do Sul.

Kirk, J.T.O. 2011. Light and Photosynthesis in aquatic ecosystems. Cambridge, Cambridge University Press, 649p.

Lissner, J.B. \& Guasselli, L.A. 2013. Variação do Índice de vegetação por Diferença Normalizada na Lagoa Itapeva, Litoral Norte do Rio Grande do Sul, a partir de séries temporais. Sociedade \& Natureza, 25(2): 427-440.

Livi, F.P. 1998. Elementos do clima: o contraste dos tempos frios e quentes. In: Menegat, R., Porto, M.L., Carraro, C.C., Fernandes, L.A.D. (Ed.). Atlas Ambiental de Porto Alegre. Porto Alegre, Universidade Federal do Rio Grande do Sul, p. 73-74.

Lodhi, M.A., Rundquist, D.C., Han, L. \& Kuzila, M.S. 1997. The potential for remote sensing of loess soils suspended in surface waters. JAWRA Journal of the American Water Resources Association, 33(1): 111-117.

Londe, L.R., Novo, E.M.L.M., Calijuri, M.C. 2011. Aplicação de técnicas de Sensoriamento remoto ao estudo do fitoplâncton de águas interiores. In: Alcântara, E.H., Novo, E.M.L.M., Stech, J.L. 
(Org.). Novas tecnologias para o monitoramento e estudo de reservatórios hidrelétricos e grandes lagos. Rio de Janeiro, Parêntese, p. 219-254.

Mackinney, G. 1941. Absorption of light by chlorophyll solutions. The Journal of Biological Chemistry, 140(1): 315-322.

Markham, B.L. \& Barker, J.L. 1986. Landsat MSS and TM post-calibration dynamic ranges, exoatmospheric reflectances and at-satellite temperature. EOSAT Landsat Technical Notes, 1: 3-8. Martinez, J.M., Espinoza-Villar, R., Armijos, E., Silva Moreira, L. 2015. The optical properties of river and floodplain waters in the Amazon River Basin: Implications for satellite-based measurements of suspended particulate matter. J Geophys Res. Earth Surf, 120 (7): 1274-1287.

Mather, P. M. 1999. Computer processing of remotely-sensed images: an introduction. $2^{\mathrm{a}}$ ed. Chichester, John Wiley \& Sons, 292p.

Mattews, M.W., Bernard, S. \& Winter, K. 2010. Remote sensing of cyanobacteria-dominant algal blooms and water quality parameters in Zeekoevlei, a small hypertrophic lake, using MERIS. Remote Sensing of Envioronment, 114(1): 20702087.

Matthew, M. W., Adler-Golden, S. M., Berk, A., Felde, G., Anderson, G. P., Gorodetzky, D., Paswaters, S., Shippert, M. 2002. Atmospheric Correction of Spectral Imagery: Evaluation of the FLAASH Algorithm with AVIRIS Data. In: APPLIED IMAGERY PATTERN RECOGNITION WORKSHOP, 31., 2002, Proceedings... p. 157-163.

Menezes, P.R. \& Almeida, T. (Orgs.). 2012. Introdução ao processamento de imagens de sensoriamento remoto. Brasília, UnB, 266p.

Millipore. 2013. HAWG04700 | Membranas Filtrantes MF-Millipore. Disponível em: <http:// www.merckmillipore.com/BR/pt/product/ MF-Millipore-Membrane-Filter-mixed-cellulose-esters,MM_NF-HAWG04700?bd=1>. Acesso em: 15 dez. 2017.

Morrey, J.R. 1968. On Determining Spectral Peak Positions from Composit

Spectra with a Digital Computer. Analytical Chemistry, 40(6): 905-914.

Nicolodi, J.L., Toldo Jr., E. \& Farina, L. 2010. Dinâmica e ressuspensão por ondas no Lago Guaíba (RS, Brasil) e implicações nos locais de captação de água para abastecimento humano. Pesquisas em Geociências, 37(1): 25-39.

Novo, E.M.L.M. \& Tundisi, J.G. 1988. Sensoriamento remoto de Águas interiores: Perspectivas. In: SIMPÓSIO BRASILEIRO DE SENSORIAMENTO REMOTO, 5.,1988, Natal. Anais... São José dos Campos, SBSR, p. 13-21.

NRSA. National Remote Sensing Agency. 2003. IRS -P6 Data User's Manual. India,142p.

Oliveira, B.S. \& Mataveli, G.A.V. 2013. Avaliação do desempenho dos classificadores Isoseg e Bhattacharya para o mapeamento de áreas de cana-de-açúcar no município de Barretos-SP. In: SIMPÓSIO BRASILEIRO DE SENSORIAMENTO REMOTO, 16., 2013, Foz do Iguaçu. Anais... Foz do Iguaçu, SBSR, p. 89-96.

Paranhos, R. 1996. Alguns métodos para análise de água. Rio de Janeiro, UFRJ, Sub-Reitoria de Ensino de Graduação e Corpo Discente/SR-1, 200p. (Cadernos didáticos).

Paz, A.R., Reis, L.G.M. \& Lima, H.V.C. 2005. Uso de modelagem hidrodinâmica visando a segmentação de corpos d'água rasos para enquadramento: o caso do lago Guaíba (RS). In: SIMPÓSIO BRASILEIRO DE RECURSOS HÍDRICOS, 16., 2005, João Pessoa. Anais...João Pessoa. Disponível em: <http://www.ct.ufpb.br/ adrianorpaz/artigos/Paz_et_al_SBRH_2005a.pdf $>$. Acesso em: 11 out. 2014.

Preisendorfer, R.W. 1986. Secchi disk science: visual optics of natural waters. Limnology and Oceanography, 31(1): 909-926.

Rodrigues, T.W.P., Guimarães, U.S., Rotta, L.H.S., Watanabe, F.S.Y., Alcântara, E. \& Imai, N.N. 2016. Delineamento amostral em reservatórios utilizando imagens Landsat-8/OLI: Um estudo de caso no reservatório de Nova Avanhandava (Estado de São Paulo, Brasil). Boletim de Ciências Geodésicas, 22(2): 303-323.

Rossato, M.S. 2011. Os climas do Rio Grande do Sul: variabilidade, tendências e tipologia. Porto Alegre, 240p. Tese de Doutorado, Programa de Pós-Graduação em Geografia, Instituto de Geociências, Universidade Federal do Rio Grande do Sul.

Rudorff, C.M., Novo, E.M.L.M., Galvão, L.S. \& Pereira Filho, W. 2007. Análise derivativa de dados hiperespectrais medidos em nível de campo e 
orbital para caracterizar a composição de águas opticamente complexas na Amazônia. Acta Amazônica, 37(2): 269-280.

Rundquist, D.C., Han, L., Schalles, J.F. \& Peake, J.S. 1996. Remote measurement of algal chlorophyll in surface waters: the case for the first derivative of reflectance near $690 \mathrm{~nm}$. Photogrammetric Engineering \& Remote Sensing, 62(2): 195-200.

Santos, F.C. 2012. Influência dos Constituintes Opticamente Ativos na Reflectância Espectral da Água do Reservatório Passo Real, RS. Santa Maria, 89p. Dissertação de Mestrado, Programa de Pós-Graduação em Geografia, Centro de Ciências Naturais e Exatas, Universidade Federal de Santa Maria.

Smith, W.S., Espíndola E.L.G. \& Rocha O. 2014. Environmental gradient in reservoirs of the medium and low Tietê River: limnological differences through the habitat sequence. Acta Limnologica Brasiliensia, 26(1): 73:88.

Steffen, C.A., Moraes, E.C., Gama, F.F. 1996. Radiometria Óptica Espectral. In: SIMPÓSIO BRASILEIRO DE SENSORIAMENTO REMOTO, 8., 1996, Salvador. Anais... Salvador, SBSR, p. 1-26.

Tang, J.W., Tian, G.L., Wang, X.Y., Wang, X.M., \& Song, Q.J. 2004. The methods of water spectra measurement and analysis I: above water method. Journal of Remote Sensing-Beijing, 8(1): 37-44.

Toldo Jr., E.E. \& Almeida, L.E.S.B. 2009. Rio guaíba. Disponível em: < lproweb.procempa.com.br/ pmpa/prefpoa/dmae/usu_doc/rioguaiba_eliriotoldojr.pdf $>$. Acesso em: 05 de Junho de 2015.

Tsai, F. \& Philpot, W.D. 1998. Derivative analysis of hyperspectral data. Remote Sensing of Environment, 66(1): 41-51.

Volpe, V., Silvestri, S. \& Marani M. 2011. Remote sensing of suspended sediment concentration in shallow Waters. Remote Sensing of Environment, 115(2011): 44-54.

Wachholz, F. 2011. Influência da bacia hidrográfica e características espaço-temporais de variáveis limnológicas sobre reservatórios no Rio Jacuí $R S$. Rio Claro, 197p. Tese de Doutorado, Programa de Pós-Graduação em Geografia, Universidade Estadual Paulista.
Wang, J. \& Tian, Q. 2015. Estimation of total suspended solids concentration by hyperspectral remote sensing on Liaodong Bay. Indian Journal of Geo-Marine Science, 44(8): 1137-1144.

Wang, Z., Kawamura, K., Sakuno, Y., Fan, X., Gong, Z. \& Lin, J. 2017. Retrieval of chlorophyll-a and total suspended solids using iterative stepwise elimination partial least squares (ISE-PLS) regression based on field hyperspectral measurement in irrigation ponds in Higashihiroshima, Japan. Remote Sensing, 9(264):1-14.

Wu, J., Ho, C., Huang, C., Srivastav, A.L., Tzeng, J. \& Lin, Y. 2014. Hyperspectral Sensing for Turbid Water Quality Monitoring in Freshwater Rivers: Empirical Relationship between Reflectance and Turbidity and Total Solids. Sensors, 14(12):22670-22688.

Yunes, J. S., \& Araújo, E. A. C. (s/d). Protocolo para análise de clorofila-a na água. Rio Grande: Unidade de Pesquisa em Cianobactérias da Universidade Federal do Rio Grande. 